\title{
Effects of methanolic extract of Pausinystalia yohimbe bark on blood glucose level in normal fasting rats
}

\author{
Hozeifa Mohamed Hassan ${ }^{1^{*}}$, Taj Eldin Imad Mohamed ${ }^{1}$, Elhadi Mohamed Ahmed ${ }^{2}$, \\ Abd Elwahab Hassan Mohamed ${ }^{3}$, Nizar Sirag ${ }^{2}$ \\ ${ }^{1}$ Department of Pharmacology, Faculty of Pharmacy, University of Gezira, Wad Medani, Sudan; \\ *Corresponding Author: hozhooz@hotmail.com \\ ${ }^{2}$ Department of Pharmacognosy, Faculty of Pharmacy, University of Gezira, Wad Medani, Sudan \\ ${ }^{3}$ Department of Pharmacology and Toxicology, Medicinal and Aromatic Plant Research Institute, National Centre of Research, \\ Khartoum, Sudan
}

Received 29 September 2012; revised 7 November 2012; accepted 17 November 2012

\begin{abstract}
Background: Pausinystalia yohimbe (L.) is a member of the family Rubiaceae. It is a valuable medicinal tree, distributed in evergreen closedcanopy forests in West Africa. It is traditionally used for treatment of erectile dysfunction and diabetes. Objective: This was an attempt to evaluate the effects of methanolic extract of $P$. yohimbe bark on blood glucose level in normal fasting rats. Methods: Different doses of methanolic extract of $P$. yohimbe bark $(5,10,20,40$ and $80 \mathrm{mg} / \mathrm{kg} / \mathrm{mL}$ ) were orally administered to normal fasting rats to assess their effects on blood glucose levels. Results: The methanolic extract of $P$. yohimbe bark in different concentrations (5, $10,20,40$ and $80 \mathrm{mg} / \mathrm{kg} / \mathrm{mL}$ ) when administered to normal fasting rats, only a considerable reduction $(26.57 \mathrm{mg} / \mathrm{dL})$ was produced by the dose of $20 \mathrm{mg} / \mathrm{kg} / \mathrm{mL}$. Conclusion and Recommendation: Although $P$. yohimbe has long been reported to regulate blood glucose levels; such effect is unclear and remains requiring further studies.
\end{abstract}

Keywords: Pausinystalia yohimbe Bark; Yohimbine; Fasting Blood Glucose Level; Hypoglycemia

\section{INTRODUCTION}

Scattered experimental studies have been undertaken worldwide to study the hypoglycemic effects of plant extracts in animal species with normal glucose levels, animals under induced states of increased blood sugar as well as in pancreatectomized animals [1,2]. Type 2 dia- betes mellitus is characterized by hyperglycemia which results from defects in insulin secretion, insulin action or both coupled with resistance to the effects of insulin [3].

The use of natural products with therapeutic properties is as ancient as human civilization and, for a long time, mineral, plant and animal products were the main sources of drugs [4]. Medicinal plants have played a key role in the world health care with about $80 \%$ of Africans depending on phytomedicine, which has shown a wide range of uses in the treatment of diseases especially priority diseases of Africa such as malaria, anemia, diabetes and hypertension. Research data on medicinal plants established that they are known to have more beneficial effects than their synthetic counterparts as being safer, convenient, affordable, culturally compatible and suitable for chronic treatments [5]. This has caused an increase in the number of experimental and clinical investigations towards the validation of the antidiabetic properties which empirically attributed to these remedies. Over 400 traditional plant treatments for diabetes have been reported, although a small number of these have received scientific and medical evaluation to assess their efficacy and safety. Of these, ginseng species, Momordica charantia (Bitter Melon), cloves, cinnamon, Trigonella foenum graecum (Fenugreek), Allium cepa (Onion) and Pausinystalia yohimbe bark have been investigated [6-11].

Yohimbine is the principal indole alkaloid extracted from the bark of the Pausinystalia yohimbe tree and found in a variety of botanical sources such as Rauwolfia root. Several potential therapeutic applications have been proposed for yohimbine, as being used in the treatment of erectile dysfunction, noninsulin-dependent diabetes mellitus, patients with orthostatic hypotension, Alzheimer's disease and depression, generalized anxiety, panic disorder and narcolepsy. Yohimbine is a potent selective 
Alpha $2\left(\alpha_{2}\right)$-adrenoceptor antagonist which may enhance insulin release [12-19]. It was mentioned that, pretreatment with yohimbine potentiates glucose-induced insulin release in normal control rats and produces an improvement of the oral glucose tolerance in diabetic rats [20].

The present study was an attempt to evaluate the effects of methanolic extract of $P$. yohimbe bark on blood glucose level in normal fasting rats.

\section{MATERIALS AND METHODS}

\subsection{Plants Material}

The dried chopped small pieces of Pausinystalia yohimbe bark had been collected from South West Cameroon in May 25 ${ }^{\text {th }}$, 2008. The plant material was authenticated by the Provincial Service for Forestry, Ministry of Forestry and Wildlife, Republic of Cameroon (Certificate No. 004/CO/MINFOF/PDFOF/PSF/SW/ 230).

\subsection{Extraction of Plant Material}

The coarsely powdered barks (500 grams) of $P$. yohimbe were extracted by maceration using pure methanol in a conical flask with continuous shaking for 72 hours, filtered and evaporated by a rotary evaporator at $60^{\circ} \mathrm{C}$. The dried extract powder was kept in an amber glass container until used for biological testing. The tested material was prepared as a water suspension to be administered to the experimental animals by intragastric feeding tubes.

\subsection{Experimental Animals}

Albino rats weighing 150 - 200 grams were purchased from National Centre of Research (NCR), Khartoum, Sudan. They were housed in a clean animal house in Faculty of Pharmacy, University of Gezira and subjected to an intensive nutritional program. Rats were acclimatized for a period of 14 days under standard environmental conditions. The animals submitted to fasting for sixteen hours prior to each experiment. They were randomly selected and divided into three groups: Group I (negative control, $\mathrm{n}=7$ ) received water, group II (positive control, $\mathrm{n}=7$ ) administered glibenclamide (5 $\mathrm{mg} / \mathrm{kg} / \mathrm{mL}$ ). The rats in group III were subdivided into five subgroups each of seven, comprising the test groups ( $\mathrm{n}=35$ ) administered different doses of methanolic extract of $P$. yohimbe bark (5, 10, 20, 40 and $80 \mathrm{mg} / \mathrm{kg} /$ $\mathrm{mL}$ ). The water suspensions of the tested materials were orally administered to the different groups of rats at 8:00 am using intragastric feeding tubes.

\subsection{Determination of Fasting Blood Glucose Levels}

The experiments were carried out according to the method developed by Tayyaba Zia et al., 2001 [21]. After gastric administration of water, glibenclamide (5 mg/kg) and different doses of methanolic extract of $P$. yohimbe bark (5, 10, 20, 40 and $80 \mathrm{mg} / \mathrm{kg} / \mathrm{mL})$, blood samples were collected from the medial vein of the tail of each rat separately at 0, 1, 2 and 4 hours. Electronic glucometer, Glucose plus (Halpern, Quebec, Canada) was used for determination of the blood glucose level.

\subsection{Data Analysis}

The obtained data were expressed as means \pm standard error of means (SEM) and analyzed using analysis of variance (ANOVA). Comparisons with the control groups were made using One-way ANOVA. Differences were considered significant if $P$-value $<0.05$.

\section{RESULTS AND DISCUSSION}

In the assessment of the effects of methanolic extract of $P$. yohimbe bark on fasting blood glucose level in normal rats, water, glibenclamide and the different doses of the extract $(5,10,20,40$ and $80 \mathrm{mg} / \mathrm{kg} / \mathrm{mL})$, were administered separately to the different groups of animals. The fasting blood glucose level for each group was determined at $0,1,2$ and 4 hours using electronic glucometer.

The administration of the methanolic extract of $P$. yohimbe bark (5, 10, 40 and $80 \mathrm{mg} / \mathrm{kg} / \mathrm{mL}$ ) separately to the tested animals, resulted in slight reductions on blood glucose level as 19.72, 18.5, 13.86 and $14 \mathrm{mg} / \mathrm{dL}$ respectively after 4 hours, compared to water and glibenclamide.

Four hours after oral administration of glibencalamide (5 mg/kg/mL), a significant reduction in fasting blood glucose levels in group II (positive control) by almost about $42.6 \mathrm{mg} / \mathrm{dL}$ was observed, as glibencalamide acts by direct induction of insulin release from the pancreatic beta cells, such a significant reduction in blood glucose levels was evident [22].

When methanolic extract of $P$. yohimbe bark in a dose of $20 \mathrm{mg} / \mathrm{kg} / \mathrm{mL}$ was used, a remarkable reduction (26.57 $\mathrm{mg} / \mathrm{dL}$ ) on the blood glucose level was produced (Table 1). This reduction may be attributed to the selective blocking activity of yohimbine at $\alpha_{2}$-adrenoceptors in the pancreas, which may enhance the rate of insulin secretion [23]. The obtained results agreed with that mentioned by Ahmed et al., (2001), who used the same dose of yohimbine $(20 \mathrm{mg} / \mathrm{kg} / \mathrm{mL})$, that potentiated glucoseinduced insulin released in normal control rats and produced an improvement of the oral glucose tolerance [14].

When the methanolic extract of $P$. yohimbe bark was given in higher doses (40 and $80 \mathrm{mg} / \mathrm{kg} / \mathrm{mL}$ ) separately to the experimental animals, it exhibited lesser reduc- 
Table 1. Effect of gastric administration of water $(5 \mathrm{~mL})$, glibenclamide $(5 \mathrm{mg} / \mathrm{kg})$ and $P$. yohimbe methanolic extract $(20 \mathrm{mg} / \mathrm{kg} / \mathrm{mL})$ on blood glucose levels in normal fasting rats.

\begin{tabular}{ccccccc}
\hline \multirow{2}{*}{ Preparations } & \multicolumn{4}{c}{$\begin{array}{c}\text { Blood glucose levels (mg/dL, mean } \pm \text { SEM) } \\
\text { (Normal value 80 - 120 } \mathbf{~ m g / d L ) ~ [ 2 4 ] ~}\end{array}$} & Reduction of glycaemia (mg/dL) & P-value \\
\cline { 2 - 7 } & $\mathbf{0 ~ h}$ & $\mathbf{1 ~ h}$ & $\mathbf{2 ~ h}$ & $\mathbf{4 ~ h}$ & 5.5 & 0.339 \\
\hline Water & $86 \pm 2.25$ & $84.33 \pm 3.67$ & $79.83 \pm 1.52$ & $80.5 \pm 3.01$ & 42.6 & 0.001 \\
Glibencalamide & $87.8 \pm 4.03$ & $62 \pm 6.15$ & $50.17 \pm 3.17$ & $45.2 \pm 3.12$ & 26.57 & 0.014 \\
\hline P. yohimbe $(20 \mathrm{mg} / \mathrm{kg} / \mathrm{mL})$ & $96.43 \pm 5.53$ & $83 \pm 6.05$ & $72.29 \pm 4.69$ & $69.86 \pm 6.8$ & & \\
\hline
\end{tabular}

tions on the blood glucose levels in normal fasting rats as 13.86 and $14 \mathrm{mg} / \mathrm{dL}$ respectively.

In this study, it was clearly evident that the highest (40 and $80 \mathrm{mg} / \mathrm{kg} / \mathrm{mL}$ ) doses of methanolic extract of $P$. yohimbe bark, caused slight lowering on the blood glucose level in normal fasting rats, whereas a considerable reduction $(26.57 \mathrm{mg} / \mathrm{dL})$ was produced by the intermediate dose $(20 \mathrm{mg} / \mathrm{kg} / \mathrm{mL})$.

The most prominent effect of $\alpha_{2}$-adrenoceptor activation is an inhibition of the release of several neurotransmitters, in particular noradrenaline [12]. In line with this, antagonism at the $\alpha_{2}$-adrenergic receptor results in an enhancement of noradrenaline release. This effect was first demonstrated for yohimbine and thereafter been shown with other antagonists too. In addition, blockade of $\alpha_{2}$-adrenoceptor by $\alpha_{2}$-adrenoceptor antagonists increases adrenergic activity centrally and peripherally [1317].

Elevation of noradrenaline, adrenaline and other more selective $\alpha_{2}$-adrenoceptor agonists inhibit insulin release and may enhance glucagon secretion. This effect is mediated mainly via the post-synaptic $\alpha_{2}$-adrenoceptors on the pancreatic beta-cells [25-27]. According to this effect, the higher doses of methanolic extract of $P$. yohimbe bark (40 and $80 \mathrm{mg} / \mathrm{kg} / \mathrm{mL}$ ) may facilitate glucagon secretion and thus lesser reduction in blood glucose level was obtained. It was reported that, yohimbine may cause gradual increases in glucagon secretion [28-31].

It can be concluded that methanolic extract of $P$. yohimbe bark decreased the blood glucose level in normal fasting rats but without significant hypoglycemic effects, therefore, further studies are required to explain this effect.

\section{REFERENCES}

[1] Ivorra, M.D., Paya, M. and Villa, A. (1989) A review of natural products and plants as potential antidiabetic drugs. Journal of Ethnopharmacology, 27, 243-275. doi:10.1016/0378-8741(89)90001-9

[2] Marles, R.J. and Farnsworth, N.R. (1995) Antidiabetic plants and their active constituents. Phytomedicine, 2, 119-189. doi:10.1016/S0944-7113(11)80059-0

[3] American Diabetes Association (2001) Hyperglycemic crises in patients with diabetes mellitus. Diabetic Care, 24, S83-S90.

[4] Rates, S.M.K. (2001) Plants as source of drugs. Toxicon, 39, 603-613. doi:10.1016/S0041-0101(00)00154-9

[5] Okigbo, R.N. and Mmeka, E.C. (2006) An appraisal of phytomedicine in Africa. King Mongkut's Institute of Technology Ladkrabang Science and Technology Journal, 6, 83-94.

[6] Bailey, C.J. (1988) Metformin revisited: Its action and indications for use. Diabetes Medication, 5, 315-320. doi:10.1111/j.1464-5491.1988.tb00996.x

[7] Bordia, M. and Verma, S.K. (1980) Effects of garlic feeding on regression of experimental atherosclerosis in rabbits. Artery, 7, 428-437.

[8] Ali, M. and Thomson, B. (1995) Consumption of a garlic clove a day could be beneficial in prevention thrombosis. Prostaglandins Leukotrienes \& Essential Fatty Acids, 53, 211-212. doi:10.1016/0952-3278(95)90118-3

[9] Dorant, E., Van den, B., Dorant, P.A. and Goldbohm, R.A. (1995) Allium vegetable consumption, garlic supplement intake, and female breast carcinoma incidence. Breast Cancer Research Treatment, 33, 163-170. doi:10.1007/BF00682723

[10] Eldin, I.M.T., Ahmed, E.M. and Abd Elwahab, H.M. (2009) Hypoglycemic activity and regeneration of pancreatic beta-cells produced by Allium cepa in alloxaninduced diabetic rats. Omdurman Journal of Pharmaceutical, 1, 562-568.

[11] Khan, A., Mahpara, S. and Mohamed, M. (2003) Cinnamon improves glucose and lipids of people with type 2 . Diabetes Care, 26, 3215-3218. doi:10.2337/diacare.26.12.3215

[12] Tam, S.W., Worcel, M. and Wyllie, M. (2001) Yohimbine: A clinical review. Pharmacology and Therapeutics, 9, 215-243. doi:10.1016/S0163-7258(01)00156-5

[13] Aantaa, R. (2000) Alpha ${ }_{2}$-adrenoceptor antagonists. Baillière's Clinical Anesthesiology, 14, 285-292.

[14] Abdel-Zaher, A.O., Ahmed, I.T. and El-Koussi, A.D. (2001) The potential antidiabetic activity of some alpha-2 adrenoceptor antagonists. Pharmacological Research, 44, 397-409. doi:10.1006/phrs.2001.0870

[15] O’Byrne, S. and Feely, J. (1990) Effects of drugs on glucose tolerance in non-insulin-dependent diabetics (Part I). Drugs, 40, 6-18. doi:10.2165/00003495-199040010-00002

[16] Coull, J.T. (1994) Pharmacological manipulation of the 
alpha2-noradrenergic system. Effects on cognition. Drugs and Aging, 5, 116-126.

doi:10.2165/00002512-199405020-00005

[17] Grossman, E., Rosenthal, T., Peleg, E., Holmes, C. and Goldstein, D.S. (1993) Oral yohimbine increases blood pressure and sympathetic nervous outflow in hypertensive patients. Journal of Cardiovascular Pharmacology, 22, 22-26. doi:10.1097/00005344-199307000-00004

[18] Venn, R.M., Bradshaw, C.J. and Spencer, R. (1999) Preliminary UK experience of dexmedetomidine, a novel agent postoperative sedation in the intensive care unit. Anesthesia, 54, 1136-1142. doi:10.1046/j.1365-2044.1999.01114.x

[19] Rang, H.P., Dale, M.M., Ritter, J.M. and Flower, R.J. (2007) Drugs affecting major organ systems. 6th Edition, Churchill Livingstone, London.

[20] Schafers, R.F., Nurnberger, J. and Herrmann, B. (1999) Adrenoceptors mediating the cardiovascular and metabolic effects of alpha-methylnoradrenaline in humans. Journal of Pharmacology and Experimental Therapeutics, 289, 918-925.

[21] Zia, T., Hasnain, S.N. and Hassan, S.K. (2001) Evaluation of the oral hypoglycemic effect of Trigonella foenumgraecum L. (methi) in normal mice. Journal of Ethnopharmacology, 75, 191-195. doi:10.1016/S0378-8741(01)00186-6

[22] Katzung, G.B. (2004) Basic and clinical pharmacology. Endocrine drugs. 9th Edition, McGraw-Hill, Philadelphia.

[23] Berridge, T.L., Collins, P.D. and Roach, A.G. (1989) Effects of efaroxan, an alpha-2 adrenoceptor antagonist, on insulin release in conscious rats. British Journal of Pharmacology, 96, 288P-293P.
[24] Ann, T.P. (1989) Determination of clinical glucose, serum cholesterol and Insulin levels. Clinical Biochemistry, 6, 24-28.

[25] Angel, I., Bidet, S. and Langer, S.Z. (1988) Pharmacological characterization of the hyperglycemia induced by alpha2-adrenergic agonists. Journal of Pharmacology and Experimental Therapeutics, 246, 1098-1103.

[26] Aantaa, R. and Scheinin, M. (1993) Alpha2-adrenergic agents in anaesthesiology. Acta Anaesthesiologica Scandinavica, 37, 433-448.

[27] Maze, M. and Tranquilli, W. (1991) Alpha-2-adrenoceptor agonists: Defining the role in clinical anesthesia. Anesthesiology, 74, 581-605. doi:10.1097/00000542-199103000-00029

[28] Andrade, S.F., Sakate, M., Laposy, C.B. and Sangiorgio, F. (2006) Yohimbine and atipamezole on the treatment of experimentally induced amitraz intoxication in cats. The International Journal of Applied Research in Veterinary Medicine, 4, 200-208.

[29] Ribes, G., Dominique, H.B., Gross, R., Blayac, J.P. and Marie-Madeleine, L.M. (1989) Involvement of a central nervous pathway in yohimbine-induced insulin secretion. European Journal of Pharmacology, 162, 207-214. doi:10.1016/0014-2999(89)90283-5

[30] Nakadate, T., Muraki, T. and Kato, R. (1980) Effect of $\alpha$ and $\beta$-adrenergic blockers on chlorpromazine-induced elevation of plasma glucose and cyclic AMP in fed mice. Japan Journal of Pharmacology, 30, 199-206. doi:10.1254/jjp.30.199

[31] Clutter, W.E., Rizza, R.A., Gerich, J.E. and Cryer, P.E. (1988) Regulation of glucose metabolism by sympathochromaffin catecholamines. Diabetes/Metabolism Review, 4, 1-15. 